\title{
Cardiac arrhythmias following pneumonectomy
}

\author{
J ØR GEN STOU G \& R D
}

From the Department of Thoracic Surgery, Bispebjerg Hospital, Copenhagen, Denmark

A series of 260 patients who underwent pneumonectomy for cancer of the lung was analysed for post-operative arrhythmias. Of these patients $28 \%$ developed such arrhythmias, usually in the form of atrial fibrillation, on the first to third post-operative day, rapidly yielding to fast-acting digitalis preparations. Possible aetiological factors were investigated, but no single cause was demonstrable. The indication for pre-operative digitalization, if any, is discussed.

Arrhythmias are fairly common following thoracic surgery. Numerous analyses on patients with diseases of the lung have shown that the incidence increases with the extent of the procedure, from $5 \%$ after lobectomy to about 30\% after pneumonectomy (Cohen and Pastor, 1957; Mowry and Reynolds, 1964). Aetiological theories are many and not always equally well founded. Among the more plausible and well substantiated ones there are:

(1) advancing age (Cohen and Pastor, 1957; Currens, White, and Churchill, 1943 ; Massie and Valle, 1947 ; Mowry and Reynolds, 1964);

(2) extent of operation (Mowry and Reynolds, 1964) ;

(3) co-existing heart disease (Burman, 1965; Cohen and Pastor, 1957 ; Dodd, Sims, and Bone, 1962 ; Mowry and Reynolds, 1964).

Moreover, a number of more hypothetical factors have been advanced, e.g.,

(4) reduction in the pulmonary vascular bed (Cerney, 1957) ;

(5) hypoxia (Cerney, 1957 ; Jacoby, Ziegler, Hamelberg, Mogg, Klassen, and Flory, 1955; Krosnick and Wasserman, 1955) ;

(6) emphysema (Wheat and Burford, 1961) ;

(7) mediastinal shift (Bailey and Betts, 1943);

(8) irritation, in some cases with local infection, around nerves (especially the vagus nerve), vessels, and arteries (Bailey and Betts, 1943; Cohen and Pastor, 1957; Jacoby et al., 1955 ; Massie and Valle, 1947);

(9) tumour implantation in the pericardium (Cohen and Pastor, 1957) ;

(10) influence of anaesthetic (Erlanger, 1962).

Most of these authors have found the arrhyth- mias to be as a rule atrial, occurring a few days $\mathcal{D}$ after the operation, and transient. The electro- $\frac{\mathbb{D}}{\mathbb{D}}$ cardiographic changes consisted mainly in the $\frac{\mathbb{D}}{3}$ various forms of arrhythmia; but persistent? changes have also been reported. Oka, Raunio, and Savola (1962) observed, following resection 8 of the lung for tuberculosis, changes that indi-e cated hypertrophy of the right heart. Killing ando Becker (1957) have also demonstrated changes several years after the operation.

\section{PRESENT INVESTIGATION}

The material comprises patients who underwent pneumonectomy for cancer of the lung during the period 1959 to 1963 in the Oeresund Chest Hospita and in the Department of Thoracic Surgery, Bispe bjerg Hospital, Copenhagen. The patients did not have a follow-up in the ordinary sense of the word, as $i \stackrel{R}{2}$ was only the period up to a few months after the operation which was of interest in connexion with? post-operative arrhythmias.

The patients totalled 260 (one record is missing so that the patient was excluded from the analysis) 3 24 women and 236 men. The age distribution io apparent from Table $I$.

In 135 cases the pneumonectomy was right-sided in 125 cases left-sided. The tumour originated in the upper or middle lobe in 158 cases and in the loweN lobe in 102. In several cases its origin was difficult to decide because of invasion into the adjacent areaso so that these figures have to be considered witlis reserve. The histology did not differ from that found in other series, showing squamous-cell carcinoma in the majority. Forty-four patients died as a result of the operation, or within the first post-operative day $\stackrel{\Phi}{\infty}$ the causes of death were pulmonary emboli, 17 ; un controllable haemorrhage, 9 ; pulmonary oedema, $5 \frac{\overrightarrow{0}}{\overrightarrow{0}}$ aspiration into the lung, 2; cerebral embolus, $1 \frac{\mathrm{P}}{\mathrm{D}}$ cerebral metastases, 1 ; invasion of the superior ven@ cava, 1 ; perforation into the oesophagus, 1 ; whilg in 7 cases the cause was unknown. 
T A B LE I

DISTRIBUTION OF ARRHYTHMIA ACCORDING TO AGE GROUP

\begin{tabular}{|c|c|c|c|c|c|c|c|c|c|}
\hline $\begin{array}{c}\text { Age } \\
\text { (years) }\end{array}$ & $\begin{array}{c}\text { No of } \\
\text { Patients }\end{array}$ & $\begin{array}{l}\text { Atrial } \\
\text { Fibril- } \\
\text { lation }\end{array}$ & $\begin{array}{l}\text { Atrial } \\
\text { Flutter }\end{array}$ & $\begin{array}{c}\text { Atrial } \\
\text { Extra- } \\
\text { systoles }\end{array}$ & $\begin{array}{c}\text { Ventricular } \\
\text { Extra- } \\
\text { systoles }\end{array}$ & $\begin{array}{l}\text { Ventricular } \\
\text { Tachy- } \\
\text { cardia }\end{array}$ & Total & $\begin{array}{l}\text { Atrial } \\
\text { Tachy- } \\
\text { cardia }\end{array}$ & $\begin{array}{l}\text { Palpatory } \\
\text { Arrhythmia }\end{array}$ \\
\hline $\begin{array}{r}<40 \\
40-49 \\
50-59 \\
60-69 \\
70-79 \\
>80\end{array}$ & $\begin{array}{r}33 \\
22 \\
103 \\
113 \\
18 \\
1\end{array}$ & $\begin{array}{r}0 \\
1 \\
15 \\
26 \\
4 \\
0\end{array}$ & $\begin{array}{l}0 \\
0 \\
2 \\
3 \\
4 \\
0\end{array}$ & $\begin{array}{r}0 \\
0 \\
3 \\
10 \\
1 \\
0\end{array}$ & $\begin{array}{l}0 \\
1 \\
3 \\
0 \\
0 \\
0\end{array}$ & $\begin{array}{l}\mathbf{0} \\
0 \\
0 \\
3 \\
0 \\
0\end{array}$ & $\begin{array}{r}0 \\
2 \\
23 \\
42 \\
5 \\
0\end{array}$ & $\begin{array}{l}0 \\
2 \\
5 \\
4 \\
1 \\
0\end{array}$ & $\begin{array}{l}0 \\
1 \\
3 \\
7 \\
1 \\
0\end{array}$ \\
\hline Total & 260 & 46 & 5 & 14 & 4 & 3 & 72 & 12 & 12 \\
\hline
\end{tabular}

INCIDENCE OF ARRHYTHMIA AND TIME OF ONSET

Post-operative arrhythmia occurred in 96 patients (37\%). The number of arrhythmias was 112 , the same arrhythmia, or another type, occasionally occurring several times in the same patient. The types of arrhythmia were atrial fibrillation, atrial flutter, extrasystoles, atrial and ventricular tachycardia, and a group called palpatory arrhythmia. Atrial tachycardia was diagnosed when the E.C.G. showed a cardiac rate exceeding 125 , if this was not explicable by elevated temperature, reduced blood volume, or other factors. The group of palpatory arrhythmia comprises patients in whom an irregular pulse was palpated, in most cases of the perpetual type, but in whom the rhythm had reverted to normal at the subsequent E.C.G. If these two groups are excluded because they were not confirmed by E.C.G., 72 patients $(28 \%)$ exhibited arrhythmias of the above-mentioned types.

T A B LE I I

TIME OF ONSET OF ARRHYTHMIA

\begin{tabular}{l|c|c|c|c|c|c}
\hline & $\begin{array}{c}\text { No. of } \\
\text { Arrhy- } \\
\text { thmias }\end{array}$ & \multicolumn{7}{c}{ Days } \\
\cline { 3 - 6 } & 1 & 2 & 3 & 4 & 5 \\
\hline $\begin{array}{c}\text { Atrial } \\
\text { fibrillation }\end{array}$ & 46 & 4 & 15 & 11 & 5 & 11 \\
$\begin{array}{c}\text { Atrial } \\
\text { flutter }\end{array}$ & 5 & 2 & 1 & 2 & 0 & 0 \\
$\begin{array}{c}\text { Atrial } \\
\text { extrasystoles }\end{array}$ & 14 & 8 & 2 & 0 & 2 & 2 \\
$\begin{array}{c}\text { Ventricular } \\
\text { extrasystoles }\end{array}$ & 4 & 3 & 0 & 1 & 0 & 0 \\
$\begin{array}{c}\text { Ventricular } \\
\text { tachycardia }\end{array}$ & 3 & 3 & 0 & 0 & 0 & 0 \\
\hline
\end{tabular}

Table I gives the distribution within the various age groups. Table II shows on which post-operative day the arrhythmia occurred, and Table III sets out its duration. Seven cases of atrial fibrillation were observed after the tenth post-operative day. In one case the fibrillation lasted for 30 days and in another for 37 days. In several instances the onset of the arrhythmia was associated with pallor, sweating, unrest, and dyspnoea, but these initial signs cannot be assessed in detail on the basis of the case sheets.

T A B L E I I I

'DURATION OF ARRHYTHMIAS

\begin{tabular}{l|r|r|r|r|r}
\hline & \multicolumn{5}{|c}{ Days } \\
\cline { 2 - 5 } & 1 & 2 & 3 & $4-10$ & $>10$ \\
\hline Atrial & 9 & 12 & 8 & 12 & 5 \\
$\quad$ fibrillation & 1 & 1 & 0 & 3 & 0 \\
$\begin{array}{c}\text { Atrial flutter } \\
\text { Atrial } \\
\text { extrasystoles }\end{array}$ & 6 & 2 & 3 & 2 & 1 \\
$\begin{array}{c}\text { Ventricular } \\
\text { extrasystoles }\end{array}$ & 2 & 1 & 0 & 1 & 0 \\
Ventricular \\
tachycardia & 1 & 1 & 0 & 1 & 0 \\
\hline
\end{tabular}

All patients with fibrillation and flutter were routinely treated with deslanoside (Cedilanid) intravenously, followed by oral digitalis medication. On this treatment the rhythm returned to normal in the course of hours or days in all but nine patients who had rhythm disturbances prior to the operation. Two of the three cases of ventricular tachycardia were fatal. Extrasystoles did not require treatment. Only four patients had been on digitalis before the operation ; two of them developed arrhythmia.

Various analyses were done in an attempt to demonstrate factors which might influence the occurrence of arrhythmia. From a practical point of view, these factors may be divided into three main groups.

\section{PRE-OPERATIVE FACTORS}

(1) As is apparent from Table I, the incidence of arrhythmia increased with age.

(2) There was no demonstrable sex difference.

(3) Abnormal cardiac history (antecedent cardiac infarction in 5, angina pectoris in 8, manifest arrhythmia in 5, exertional dyspnoea in 6, tendency to leg oedema in 8) : Such a history was given by 32 patients, 13 of whom ( $40 \%$ ) developed arrhythmia. Out of 14 patients with a tendency to oedema and/or exertional dyspnoea, 9 (67\%) developed arrhythmia. 
(4) Hypertension (blood pressure exceeding 170/ $100 \mathrm{~mm}$. $\mathrm{Hg}$ ) was present in 10 cases and did not give rise to an increased incidence of arrhythmia.

(5) E.C.G. changes in the three extremity leads, in the form of a depressed ST segment in two of three leads, were present in 34 patients, 14 (41\%) of whom developed arrhythmia. Negative $T_{1} / T_{2}$ was present in 10 cases, half of whom developed arrhythmia. Changes such as axis deviation (43 cases), flat $T$ waves (8 cases), deep $Q_{3}$ ( 2 cases), left-sided bundle-branch block (3 cases), Bailey's bundle-branch block (1 case), or low voltage (5 cases) did not influence the incidence of cardiac arrhythmia.

(6) Pre-operative arrhythmia was present, as already mentioned, in nine cases ( 8 of extrasystoles and 1 of atrial fibrillation). Post-operatively, all nine patients continued to have arrhythmia which persisted throughout the observation period.

(7) Generalized arteriosclerosis, of varying severity, was found in 13 patients, three $(23 \%)$ of whom developed arrhythmia.

(8) Tests of lung function were done in all cases, and, in the event of abnormal findings, they were supplemented by determinations of oxygen and carbon dioxide in the blood. In 113 cases these tests showed 'slightly reduced lung function of the restrictive type'. Out of these patients 40 $(35 \%)$ developed arrhythmia.

OPERATIVE FACTORS The operative technique was in broad features the same in all cases. With the patient lying on his side, the fifth or sixth rib was resected, and if possible the entire tumour was removed and so were any involved lymph nodes. Where the tumour was situated in close relation to or invading the pericardium or atrium (Hansen, Jensen, and Kjaer, 1961), these structures were partially resected. At last, a thick rubber drain was inserted in order thereby to control possible post-operative haemorrhage. The drain was connected to a special system of bottles which automatically regulates the pressure in the pneumonectomy cavity to $-10 \mathrm{~cm}$. of water. The drain was removed within the first 24 hours.

(1) Anaesthetic factors were not studied in detail. Considering that most arrhythmias occurred several days after the operation, when the anaesthetic agents had been eliminated from the body, this factor can hardly be of essential importance in the genesis of the arrhythmia.

(2) Arrhythmia occurred during the operation in six patients (in the form of atrial fibrillation in 2 , extrasystoles in 3 , and ventricular tachy- cardia in 1). All six patients exhibited the same arrhythmias during the post-operative period. 흠 Routine E.C.G. tracings were not done during $\frac{\bar{\sigma}}{\sigma}$ the operations, so there is a possibility that further $\stackrel{\Phi}{\Omega}$ arrhythmias have occurred but have escaped detection.

(3) The severity of operative trauma was assessed, tentatively, on the basis of the number $\vec{\omega}$ of blood transfusions required during and immediately after the operation:

Of 184 patients who received $500-2,000 \mathrm{ml}$. blood 46 developed arrhythmia $(25 \%)$. if

Of 53 patients who received 2,500-4,000 ml. ज़ blood 17 developed arrhythmia (32\%).

Of 23 patients who received more than 4,000 의 ml. blood 9 developed arrhythmia $(40 \%)$.

(4) The pericardium was opened in 71 patients, $\mathbb{D}$ 38 of whom had further resection of the peri- $\frac{\mathbb{D}}{\mathbb{D}}$ cardium. Of these, $20(28 \%)$ and $14(37 \%)$ respec- $\frac{\mathbb{D}}{3}$ tively developed arrhythmia.

(5) Atrial resection was done on 21 patients, $\stackrel{\Phi}{\sim}$ eight $(38 \%)$ of whom developed arrhythmia.

(6) The histological architecture of the tumour, its situation in the right or left lung, in the upper 0 + middle lobe or in the lower lobe showed no difference in the incidence of arrhythmia.

(7) Radically operated patients do not appear to have been spared arrhythmia any more than patients in whom it was not possible to remove all cancerous tissue.

\section{POST-OPERATIVE FACTORS}

(1) The removal of the drain within the first 24 hours did not give rise to arrhythmia, which in most cases occurred one or two days later.

(2) Elevation of temperature to $38^{\circ}-39^{\circ} \mathrm{C}$. was fairly common, but in most cases the temperature $\delta$ had returned to normal when the arrhythmia set in.

(3) Stagnation of secretion in the airways indicated tracheal toilet in 58 patients, and in six of these cases even tracheostomy. Out of this group $22(38 \%)$ developed arrhythmia.

(4) Haemorrhage and transient infection, with $N$ or without mediastinal shift, occurred in 39 స్ patients who later underwent one or several paracenteses emptying out varying quantities of fluid. Out of these patients $14(36 \%)$ developed arrhythmia.

\section{POST-OPERATIVE E.C.G. CHANGES}

In addition to the actual arrhythmia, the following E.C.G. abnormalities were observed: axis 
deviation occurred in 25 patients (left-sided in 22 and right-sided in 3); depression of ST was more common in patients who later developed arrhythmia. Thus, 36 showed depression of $\mathrm{ST}_{1+2}$ and 17 depression of $\mathrm{ST}_{1+2+3}$, and of these groups $22(61 \%)$ and $14(82 \%)$ respectively developed arrhythmia. Negative $T_{1} / T_{2}$ and change of a positive $T_{3}$ into negative occurred in 53 and 39 patients, $30(57 \%)$ and $17(45 \%)$ of whom developed arrhythmia. Low voltage was found in eight patients, two of whom later developed rhythm disturbances $(25 \%)$. There were seven cases of bundle-branch block (4 left-sided and 3 right-sided) and five cardiac infarctions (3 anterior-wall and 2 posterior-wall).

\section{PERICARDIAL AFFECTION}

Several authors (Epstein, 1957; Hammel and Lyons, 1962 ; Ito, Engle, and Goldberg, 1958 ; Milstein and Brock, 1955; Wolff and Grunfeld, 1963) have reported a symptom complex called 'post-commissurotomy syndrome' or 'post-pericardiotomy syndrome' after cardiac as well as non-cardiac thoracic surgery. The symptoms have occurred one to four weeks after the operation or severe thoracic trauma in the form of slight fever, chest pain radiating into the back, weak cardiac sounds, in some cases with pericardial friction, E.C.G. changes, and arrhythmia. The aetiology is unknown. The condition is considered to originate mainly in the pericardium; bleeding in the pericardium, virus infection, and sensitivity reaction have been suggested. In the present material it was not possible to demonstrate clinical or electrocardiographic signs of pericardial involvement. The necropsy records for 98 of the patients have been procured. Forty-four were reported to have shown pericardial changes of varying intensity, from a rough surface to total synechiae, and in eight there was also cancer tissue in the pericardium. Of these patients, 37 had had pericardial surgery. Twenty-one of all 44 developed arrhythmia (48\%). Out of the 54 patients without pericardial changes, 14 had had operation on the pericardium, and the incision had apparently healed without visible changes. Of this group 15 developed arrhythmia (28\%).

In order to demonstrate, if possible, a state of hypoxia in connexion with the onset of arrhythmia, 10 patients had daily determinations of oxygen and carbon dioxide in the arterial blood as well as E.C.G. tracings. Four developed arrhythmia without having exhibited abnormal blood values.

\section{DISCUSSION}

The results show that the arrhythmias arise mainly within the first four days, that they last for only a fairly short time (one to three days), that they are usually in the form of atrial fibrillation, and that they yield to intravenous digitalis. It was not possible to find a decisive cause for their occurrence, but several factors appear to increase the tendency. There was an increased number of cases of advancing age, perhaps caused by the greater frequency of heart disease in the elderly. A tendency to oedema, dyspnoea, and E.C.G. changes, in the form of depression of ST in two of the three extremity leads or a negative $T_{1} / T_{2}$, is associated with an increased tendency to arrhythmia. The number of arrhythmias was also increased in the presence of reduced lung function, measured pre-operatively by spirometry and related post-operatively to the indication for tracheal toilet and/or tracheostomy. The severity of the operation and operation on the pericardium and atrium, perhaps causing pericarditis demonstrable post mortem, also entail an increased inoidence of arrhythmias. It might be imagined that the state of irritation in the pericardium encroaches upon the myocardium, thus affecting the conduction system.

As already mentioned, 17 patients died within the first week from pulmonary emboli. Seven of these patients had arrhythmia in the form of fibrillation during the terminal days. It cannot be disregarded that in these cases the arrhythmia may have had a detrimental effect. It is probable that, if untreated, the arrhythmia would have aggravated the patient's condition, but when quickly and adequately treated it does not seem to cause any long-standing aggravation. Therefore, the question concerning possible preoperative digitalization of all patients cannot be answered consistently. On the one hand, a fastacting digitalis preparation can control practically all arrhythmias. But the patient's general condition is somewhat affected, especially at the time of the onset of the arrhythmia, and the abovementioned number of fatal pulmonary emboli must be borne in mind. Digitalization might, therefore, be considered in the hope of reducing the number of post-operative arrhythmias in particularly predisposed patients, i.e., elderly patients with an abnormal cardiac history, E.C.G. changes in the form of ST depression and/or negative $T_{1} / T_{2}$. This also applies to patients who require a fairly large number of blood transfusions during the operation, in whom the operation 
involves surgery on the pericardium or atrium, or patients who post-operatively accumulate large quantities of secretion in the air passages.

\section{REFERENCES}

Bailey, C. C., and Betts, R. H. (1943). Cardiac arrhythmias following pneumonectomy. New Engl. J. Med., 229, 356.

Burman, S. O. (1965). Digitalis and thoracic surgery. J. thorac. cardiovasc. Surg., 50, 873.

Cerney, C. I. (1957). The prophylaxis of cardiac arrhythmias complicating pulmonary surgery. J. thorac. Surg., 34, 105.

Cohen, M. G., and Pastor, B. H. (1957). Delayed cardiac arrhythmias following non-cardiac thoracic surgery. Dis. Chest, 32, 435.

Currens, J. H., White, P. D., and Churchill, E. D. (1943). Cardiac arrhythmias following thoracic surgery. New Engl. J. Med., 229, 360 .

Dodd, R. B., Sims, W. A., and Bone, D. J. (1962). Cardiac arrhythmias observed during anesthesia and surgery. Surgery, 51, 440

Epstein, S. (1957). Is the postcommissurotomy syndrome of rheumatic origin? Arch. intern. Med., 99, 253.

Erlanger, H. (1962). Cardiac arrhythmias in relationship to anesthesia: past and present concepts. Amer. J. Med. Sci., 243, 651 .

Hammel, C. L., and Lyons, W. S. (1962). Postpericardiotomy syndrome. Amer. J. Dis. Child., 104, 385.

Hansen, J. L., Jensen, H. E., and Kjaer, T. (1961). Resection of the left atrium of the heart during pneumonectomy for bronchogenic carcinoma. Acta chir. scand. Suppl., 283, 111.
Ito, T., Engle, M. A., and Goldberg, H. P. (1958). Postpericardiotc syndrome following surgery for nonrheumatic heart diseaso Circulation, 17, 549.

Jacoby, J., Ziegler, C., Hamelberg, W., Mogg, A., Klassen, K., a Flory, F. (1955). Cardiac arrhythmia: effect of vagal stimulation and hypoxia. Anesthesiology, 16, 1004.

Killing, F., and Becker, W. H. (1957). Elecktrokardiographisc Untersuchungen bei Pneumonektomierten. Thoraxchirurgie, $5,46$.

Krosnick, A., and Wasserman, F. (1955). Cardiac arrhythmias in the older age group following thoracic surgery. Amer.J. Med. $S c i$., 230, 541 .

Massie, E., and Valle, A. R. (1947). Cardiac arrhythmias comp cating total pneumonectomy. Ann. intern. Med., 26, 231.

Milstein, B. B., and Brock, R. (1955). The operative managerent $\not$ f pulmonary valvotomy for pulmonary valve stenosis with nol nid aortic root. Guy's Hosp. Rep., 104, 1

Mowry, F. M., and Reynolds, E. W. (19€4). Cardiac thythm dist UY bances complicating resectional surgery of the ling. Ann. intefyl] Med., 61, 688 .

Oka, M., Raunio, H., and Savola, P. (1962). Appearance of electrocardiographic signs of right atrial enlargement and right vent cular hypertrophy after pulmonary resection in tuberculosis. Acta tuberc. pneumol. scand., 41, 176.

Wheat, M. W., and Burford, T. H. (1961). Digitalis in surgerf extension of classical indications. $J$. thorac. cardiovasc. Sur 41, 162.

Wolff, L., and Grunfeld, O. (1963). Pericarditis. New Engl. J. Me $\$$ 268, 419. 